\title{
Metabolic disease with autoimmune phenomena: 2 cases of SLE-like disease in young children diagnosed with lysinuric protein intolerance
}

\author{
C Sengler*1, J Gellermann², J Hennermann ${ }^{3}$ and R Keitzer ${ }^{1}$
}

Address: ${ }^{1}$ Charité - Universitätsmedizin Berlin, Department of Pediatric Pneumology and Immunology, Berlin, Germany, ${ }^{2}$ Charité Universitätsmedizin Berlin, Department of Pediatric Nephrology, Berlin, Germany and ${ }^{3}$ Charité - Universitätsmedizin Berlin, Department of General Pediatrics, Berlin, Germany

* Corresponding author

from $15^{\text {th }}$ Paediatric Rheumatology European Society (PreS) Congress

London, UK. 14-17 September 2008

Published: 15 September 2008

Pediatric Rheumatology 2008, 6(Suppl I):P246 doi:10.1 186/1546-0096-6-SI-P246

This abstract is available from: http://www.ped-rheum.com/content/6/SI/P246

(c) 2008 Sengler et al; licensee BioMed Central Ltd.

The second son of consanguineous parents was repeatedly evaluated for failure to thrive, intermittent vomiting, diarrhea, hepatosplenomegaly and panzytopenia since his first year of life. Specific diets had no effect. Bone marrow aspiration showed hemophagocytosis, but no signs of malignancy. At the age of 6 years he developed a hemolytic uremic syndrome-like disease. Renal biopsy revealed mesangioproliferative glomerulonephritis, classified as Lupus nephritis IIa, consistent with positive findings for ANA (1:320), La-, Sm-, RNP-, histone- and phospholipid antibodies, so he received immunosuppressive therapy.

A 5-year-old Turkish girl with consanguineous parents presented with polyarthritis, fatigue, diffuse hair loss, hepatosplenomegaly and ascites; the laboratory work up showed leukopenia, Coombs-positive anemia, elevated liver enzymes, high IgG, low complement, ANA titer 1:640 with positive anti-DNA-, Ro-, U1RNP- and histoneantibodies. Diagnosis of a lupus-like disease was made and she was started on immunosuppressive therapy. Metabolic studies finally led to both patients's diagnosis: Arginine, lysine and ornithine were low in the serum, but high in the urine, casting suspicion on lysinuric protein intolerance, a rare metabolic disease characterized by failure to thrive, muscle hypotonia, vomiting, proteine avoidance and hepatomegaly. Immunologic abnormalities with positive autoantibodies, vasculitis, arthritis and glomerulonephritis have also been described. The underlying cause is a defective amino acid transport mecha- nism, leading to a lack of cationic amino acids in the serum and consecutive perturbation of the urea cycle. In the second case this diagnosis could even be confirmed by sequencing the SLC7A7 gene, revealing a new homozygous mutation (Cys427Arg). 